\title{
1 Endochondral bone in an Early Devonian 'placoderm' from Mongolia
}

2

3 Martin D. Brazeau ${ }^{1,2}$, Sam Giles ${ }^{2,3,4}$, Richard P. Dearden ${ }^{1,5}$, Anna Jerve ${ }^{1,6}$, Y.A.

4 Ariunchimeg $^{7}$, E. Zorig ${ }^{8}$, Robert Sansom ${ }^{9}$, Thomas Guillerme ${ }^{10}$, Marco Castiello ${ }^{1}$

5

$6{ }^{1}$ Department of Life Sciences, Imperial College London, Silwood Park Campus, Buckhurst

$7 \quad R d$, Ascot, SL5 7PY, UK;

$8{ }^{2}$ Department of Earth Sciences, Natural History Museum, Cromwell Road, London SW7

$9 \quad 5 B D, U K$;

$10{ }^{3}$ School of Geography, Earth and Environmental Sciences, University of Birmingham,

11 Birmingham, $U K$;

$12{ }^{4}$ Department of Earth Sciences, University of Oxford, South Parks Road, Oxford, OX1 3AN,

$13 U K$;

$14{ }^{5}$ CR2P Centre de Recherche en Paléontologie - Paris, Muséum national d'Histoire

15 naturelle, Sorbonne Universités, CNRS, CP 38, 57 Rue Cuvier, 75231, Paris, Cedex 05,

16 France

$17{ }^{6}$ Department of Organismal Biology, Subdepartment of Evolution and Development,

18 Uppsala University, Norbyvägen 18A, 75236 Uppsala, Sweden;

$19{ }^{7}$ Natural History Museum, P.O. Box 46/52, Ulaanbaatar 1420, Mongolia

$20{ }^{8}$ Institute of Paleontology, Mongolian Academy of Science, P.O. Box 46/650, S. Danzan

21 Street 3/1, Chingeltei District. Ulaanbaatar 15160, Mongolia;

$22{ }^{9}$ School of Earth and Environmental Sciences, University of Manchester, Manchester M13

$239 P T, U K$;

$24{ }^{10}$ Department of Animal and Plant Sciences, The University of Sheffield, Sheffield S10 2TN, $25 U K$ 
26 Endochondral bone is the main internal skeletal tissue of nearly all osteichthyans ${ }^{1,2}$ the group comprising more than 60,000 living species of bony fishes and tetrapods. Chondrichthyans (sharks and their kin) are the living sister group of osteichthyans and have cartilaginous endoskeletons, long considered the ancestral condition for all jawed vertebrates (gnathostomes) ${ }^{3,4}$. The absence of bone in modern jawless fishes and the absence of endochondral ossification in early fossil gnathostomes appears to lend support to this conclusion. Here we report the discovery of extensive endochondral bone in a new genus of 'placoderm'-like fish from the Early Devonian (Pragian) of western Mongolia described using x-ray computed microtomography (XR- $\mu \mathrm{CT})$. The fossil consists of a partial skull roof and braincase with anatomical details providing strong evidence of placement in the gnathostome stem group. However, its endochondral space is filled with an extensive network of fine trabeculae resembling the endochondral bone of osteichthyans. Phylogenetic analyses place this new taxon as a proximate sister group of the gnathostome crown. These results provide direct support for theories of generalised bone loss in chondrichthyans ${ }^{5,6}$. Furthermore, they revive theories of a phylogenetically deeper origin of endochondral bone and its absence in chondrichthyans as a secondary condition ${ }^{7,8}$.

Systematic palaeontology

Etymology. Generic name honours the memory of Chuluun Minjin for his extensive contributions to the Palaeozoic stratigraphy of Mongolia, his enthusiastic support of this work, and introducing us to the Yamaat River locality. Specific name recognises the provenance of the fossil from the Turgen region, Uvs aimag of western Mongolia.

Holotype. Institute of Paleontology, Mongolian Academy of Sciences MPC-FH100/9.1, a partial braincase and skull roof. of the stratigraphic sequence that occurs between the Tsagaan-Salaat and Yamaat Rivers.

59 Formation and age. Upper part of Tsagaansalaat Formation, Pragian (Early Devonian) ${ }^{9,10}$. 
61 Diagnosis. 'placoderm' -grade stem gnathostome with endochondral bone, deep epaxial

62 muscle cavities flanking a slender occipital ridge, and the following possible autapomorphies:

63 dermal bones covered in sparsely placed tubercles, penultimate spino-occipital nerve canal

64 substantially larger in diameter than others.

\section{Description}

67 MPC-FH100/9.1 consists of a partial braincase and skull roof (Fig. 1). The skull roof is 68 ornamented with sparsely distributed stellate tubercles resembling those of the Siberian

69 'placoderm' Dolganosteus ${ }^{11}$. Towards the midline of the skull roof, the tubercles are larger

70 and more pointed, and are more broadly separated from each other by unornamented fields.

71 The specimen shows signs of extensive post-mortem transport, with angles of the braincase

72 worn off and much of the skull roof and some of the braincase preserved as a mould.

73 Individual skull roof ossifications cannot be identified, although this may be due to the

74 dominantly mouldic preservation. There appears to have been a prominent nuchal plate

75 eminence comparable to acanthothoracids ${ }^{12-14}$.

77 Endoskeletal tissue. The braincase of MPC-FH100/9.1 is well ossified, comprising an

78 external bony sheath filled with an extensive matrix of spongy tissue (Fig. 2a-b; Extended

79 Data Fig. 1; Supplementary Videos 1 \& 2). The trabecles forming this tissue are irregular and

80 branching, less than $1 \mathrm{~mm}$ thick and often curved, and resemble most closely the

81 endochondral tissue of osteichthyans (Fig. 2c-d). As such, we interpret this as endochondral

82 bone. Notably, this is found in all preserved regions of the braincase, in contrast to the

83 isolated trabeculae identified as endochondral bone in Boreaspis ${ }^{15}$ and Bothriolepis ${ }^{16}$. The

84 margins of the braincase, the endocranial walls, and the boundaries of nerve and blood

85 canals, are formed from a thicker tissue which we interpret as perichondral bone. This

86 suggests that the endoskeleton of Minjinia comprises osteichthyan-like endochondral bone,

87 with an ossified perichondrium. To address the possible alternative explanation that it is an

88 aberrant instance of calcified cartilage, we compared the structure of this tissue with rarely-

89 preserved mineralized cartilage in the stem chondrichthyan Diplacanthus crassismus

90 (National Museums of Scotland specimen NMS 1891.92.334; Fig. 2e-f) observed using

91 synchrotron tomography. The cancellae within the endochondral tissue of Minjinia are

92 irregular, with a diameter of approximately $1-2 \mathrm{~mm}$. This tissue is distinctly unlike the 
93 calcified cartilage of Diplacanthus in appearance, which consists of a densely packed matrix

94 of irregularly stacked chondrons between $20-60 \mu \mathrm{m}$ in diameter.

Neurocranium. The braincase is preserved from the level of the right posterior orbital wall to the posterior end of the occipital ridge. Occipital glenoid condyles are not preserved, but broad, flat parachordal plates are present, separated by a midline groove that accommodated a relatively narrow notochordal tunnel. A transverse fissure spans the basicranial surface at

100 about mid-length of the preserved portion. It clearly demarcates the anterior margin of the

101 parachordal plates and may correspond to the ventral cranial fissure of crown-group gnathostomes. However, unlike in crown gnathostomes, it is traversed by a substantial anterior extension of the cranial notochord. The courses of the lateral dorsal aortae are marked by a pair of sulci on the lateral margins of the parachordal plates. A narrow, shallow sulcus for the efferent hyoid artery is present on the preserved right side of the specimen, immediately behind the level of the orbit (Fig. 1a).

The lateral surface of the braincase is preserved on the right side as a mouldic impression in the matrix (Fig. 1). A sharply demarcated hyoid fossa is present on the lateral wall of the otic region (Fig. 1). Posterior to this, a stout but pronounced vagal process with a pair of rounded eminences likely corresponds to the branchial arch articulations. There is no evidence for a pair of anterior and posterior divisions to the vagal process, which are typically seen in other 'placoderms'. A well-developed 'placoderm'-like craniospinal

113 process is absent; its homologous position is instead covered in perichondral bone and marked by a low ridge (Fig. 1).

115 In posterior view, a tall, narrow median otic ridge is evident and resembles the 116 morphology of Romundina ${ }^{17}$ and Arabosteus ${ }^{18}$. Similar to these taxa, the median otic ridge is 117 flanked by two large occipital fossae for the epaxial musculature. The notochordal tunnel is 118 approximately the same size as or smaller than the foramen magnum, as in 'placoderms' and 119 in contrast with crown-group gnathostomes. A metotic fissure is absent.

121 Endocast. A partial cranial endocast is preserved, consisting of the hindbrain cavity, partial 122 midbrain cavity, labyrinth cavities, and posteromedial corner of the orbital region. The two

123 primary trunk canals of the trigeminal nerve $\left(\mathrm{N} . \mathrm{V}_{1}\right.$ and $\left.\mathrm{N} . \mathrm{V}_{2,3}\right)$ are preserved (Fig. 1;

124 Extended Data Fig. 2). The acoustic (N.VIII) and facial nerve (N.VII) canals share a common 125 trunk canal behind the trigeminal nerves, as in many other 'placoderms' ${ }^{17,19-21}$. The 126 supraopthalmic branch opens into the rear wall of the orbit and part of its supraorbital course 
127 is preserved (Extended Data Figs. 2, 3). A slender branch extends below the labyrinth and

128 divides into palatine and hyomandibular branches (Extended Data Figs. 2, 3). As in other

129 'placoderm'-grade taxa, the vagus nerve (N. X) trunk canal is very large in diameter and exits

130 from immediately behind the labyrinth cavity (Fig. 1; Extended Data Fig. 2). The spino-

131 occipital region resembles other 'placoderms' in being extended. At least four spino-occipital

132 nerve canals are present in a linear series, and the penultimate canal is largest in diameter

133 (Fig. 1; Extended Data Fig. 2). Intercalating these is a network of occipital artery canals

134 branching from the dorsal aortae.

135 The skeletal labyrinth is not complete on either side of the specimen, but can mostly

136 be reconstructed according to the assumption of bilateral symmetry. The most significant

137 feature is that the labyrinth and endolymphatic cavity are joined to the main endocavity

138 chamber (Fig. 1). This is a striking contrast to other 'placoderms' and closely resembles

139 crown-group gnathostomes ${ }^{22}$. The endolymphatic canals are elongate and tubular, extending

140 posterolaterally to reach the skull roof, though external openings cannot be clearly identified.

141 The anterior semi-circular canal follows the saccular cavity closely as in petalichthyids ${ }^{23}$ (Fig.

142 1; Extended Data Fig. 2). However, the horizontal and posterior canals appear to extend well

143 away from the saccular chamber (Fig. 1, Extended Data Fig. 2). The dorsal junctions of the

144 anterior and posterior canals are joined in a crus commune, as in Romundina ${ }^{17}$ and

145 Jagorina $^{19}$. A sinus superior is absent.

\section{Phylogenetic analyses}

148 We conducted phylogenetic analyses under four different protocols: equal weights

149 parsimony, implied weights parsimony, an unpartitioned Bayesian analysis, and a Bayesian

150 analysis with characters partitioned by fit determined under implied weights parsimony ${ }^{24}$ (see

151 Extended Data Figs. 4-7). All phylogenetic analyses consistently place Minjinia as a stem-

152 group gnathostome, proximate to the gnathostome crown (Fig. 3, Extended Data Figs 4,5).

153 Equal weights parsimony recovers Minjinia in a position crownward of arthrodires but

154 outside of a grade consisting of Entelognathus, Ramirosuarezia, and Janusiscus. Under

155 implied weights, these three taxa move onto the osteichthyan stem and Minjinia is placed as

156 the immediate sister taxon of the gnathostome crown. Under Bayesian analyses, arthrodires

157 are resolved as more crownward than Minjinia. However, the latter analyses fail to recover

158 arthrodires as a clade and the node uniting them with the crown to the exclusion of Minjinia

159 is extremely weakly supported (posterior probability: 0.52-0.55). Under parsimony, the

160 crownward position of Minjinia is unambiguously supported by the skeletal labyrinth and 
161 endolymphatic duct being confluent with the main cranial cavity ${ }^{22}$ (Fig. 3). In common with

162 arthrodires and the gnathostome crown, Minjinia possesses a division of the facial nerve deep

163 to the transverse otic process (Fig. 1; Extended Data Fig. 2). However, Minjinia is excluded

164 from the gnathostome crown group due to the absence of a metotic fissure and a posterior

165 dorsal fontanelle, and presence of broad, flat parachordal plates expanded behind the saccular

166 cavity (Fig. 3, Supplementary Information).

167 We undertook ancestral states reconstructions to assess the evolutionary history of

168 endochondral bone (Fig. 3, Extended Data Figs. 6 \& 7). Interestingly, parsimony analysis

169 fails to recover secondary homology of this trait between Minjinia and osteichthyans. The

170 crownward placement of Minjinia is, in fact, based on independent evidence relating to

171 anatomical features of the braincase and endocast. However, the strict precision of parsimony

172 reconstructions makes it insensitive to underlying uncertainty. To explore this, we used

173 likelihood reconstructions and compared the ancestral state reconstructions under equal rates

174 (ER) and all rates different (ARD) variants of the Mkv model on branch-length-rescaled

175 parsimony trees and Bayesian trees. On the parsimony trees, both models show substantial

176 non-zero probabilities ( 0.23 for ER; 0.39 for ARD; Extended Data Table 1 ) for the presence

177 of endochondral bone in the common node of Minjinia and Osteichthyes (Extended Data Fig.

178 6) in the parsimony trees. The ARD model shows the best likelihood score and a better AIC

179 fit for endochondral bone (Extended Data Table 1), favouring repeated losses of this tissue

180 over multiple gains (see Discussion). The values are substantially lower in the Bayesian trees

181 (Extended Data Fig. 7, Extended Data Table 1), but this results from the relative positions of

182 Minjinia and arthordires, which is not well supported in those trees.

\section{Discussion}

185 Minjinia presents an unusual discovery of extensive endochondral bone in a 'placoderm'-

186 grade fish, with repercussions for the phylogenetic origin of this tissue and the problem of

187 early gnathostome relationships more generally. The vertebrate skeleton is split into two

188 systems: the exoskeleton (external achondral dermal bones) and endoskeleton (internal

189 chondral bones) ${ }^{1}$. Dermal bone evolved at least 450 million years ago in jawless stem

190 gnathostomes, but the endoskeleton in these taxa is not endochondrally ossified (but see

191 below). More crownward stem gnathostomes (osteostracans and 'placoderms') surround their

192 cartilaginous endoskeleton in a sheath of perichondral bone. Extant chondrichthyans lack

193 both dermal and perichondral bone, possessing a cartilaginous endoskeleton enveloped by

194 prismatic calcified cartilage. Endochondral bone, in which the cartilaginous endoskeletal 
195 precursor is invaded by and eventually replaced by bone, is widely considered an

196 osteichthyan apomorphy based on clear prior polarity ${ }^{3,7,25,26}$. However, recent work has cast

197 doubt on this assertion. The recognition that dermal bone is secondarily lost in

198 chondrichthyans ${ }^{27,28}$ is consonant with prior knowledge of the loss of perichondral bone in

199 this same lineage ${ }^{29}$. Taken together, this has revived uncertainty about the true phylogenetic

200 timing of the origin of endochondral ossification ${ }^{8}$.

201 Minjinia does not represent the first report of endochondral bone outside of

202 Osteichthyes. However, it is by far the most extensive and unequivocal example, and raises

203 explicit questions in light of the proximity of Minjinia to the gnathostome crown. Isolated

204 examples of trabecular bone, typically restricted to a small region of the neurocranium, have

205 historically been reported in boreaspid osteostracans ${ }^{15,30}$, buchanosteid arthrodires ${ }^{31}$ and

206 petalichthyids $^{32}$. However, these reports have all been dismissed as misidentifications ${ }^{26}$,

207 possibly representing the retreat of perichondral bone deposited during cartilage growth ${ }^{33}$.

208 Most recently, trabeculae in supposed endoskeletal bones of Bothriolepis have been termed

209 endochondral bone ${ }^{16}$, although the small scale of these is in line with 'superficial'

210 perichondral trabeculae seen elsewhere. In line with ref. 26, we found no evidence of

211 endochondral bone in material of Buchanosteus held in the Natural History Museum,

212 London, or indeed in any other 'placoderms' we have examined. The Epipetalichthys

213 holotype (Museum für Naturkunde, Berlin specimen MB.f.132.1-3) shows an apparently

214 spongiose infilling in the anterior region of the braincase, but the identity of this structure, or

215 even whether it is biological, cannot be determined.

216 Does endochondral bone have a deep origin within the gnathostome stem group? This

217 would imply repeated losses of this tissue. We do find some statistical support for this

218 hypothesis (Fig. 3, Extended Data Figs. 6, 7; Extended Data Table 1), and the model is well

219 justified on prior phylogenetic and biological grounds. Endochondral bone has long been

220 known to be inconsistently developed across 'primitive' bony fishes: incomplete or entirely

221 absent ossification of the endoskeleton is known in both Palaeozoic actinopterygians ${ }^{34}$ and

222 sarcopterygians $^{35}$, as well as more recent taxa ${ }^{36}$. The frequent absence of endochondral bone

223 is considered secondary, and other controlling factors such as body size, maturity, mechanical

224 stress, and buoyancy can determine its degree of development ${ }^{1}$. Our findings are also in

225 agreement with studies establishing a genetic basis for secondary loss of all bone types within

226 chondrichthyans ${ }^{5,37,38}$, with the failure to produce endochondral bone likely representing

227 arrested development of chondrocytes as opposed to a primary lack of ability ${ }^{6}$. 
Another confounding factor in this question is the problem of 'placoderm'

229

230

231

232

233

234

235

236

237

238

239

240

241

242

243

244

245

246

247

248

249

250

251

252

253

254

255

256

257

258

259

260

261 relationships. Although currently resolved as a deeply pectinate grade along the gnathostome stem, the backbone of this arrangement has poor statistical support and there is a lack of consistency in the arrangement of plesia. Minjinia itself highlights this uncertainty, given its highly unexpected character combinations. Notwithstanding its endochondral bone and crown-gnathostome-like inner ear structure, it strongly resembles 'acanthothoracids' - the 'placoderms' widely considered among the most removed from the gnathostome crown (i.e. most 'primitive'). This apparent character conflict could perhaps be more easily reconciled with a more coherent (though not necessarily monophyletic) 'placoderm' assemblage. Indeed, the highly pectinate structure of the 'placoderm' grade seems symptomatic of an overemphasis on characters and taxa resembling the crown group, thereby undersampling characters that could stabilise a clear picture of 'placoderm' interrelationships.

Minjinia reveals new data on 'placoderm' endoskeleton and tissue diversity from Mongolia — an otherwise extremely poorly known biogeographic realm for early gnathostomes. The phylogenetic placement of this 'acanthothoracid'-like taxon crownward of all non-maxillate 'placoderms', in conjunction with possession of extensive endochondral bone, highlights the importance of material from traditionally undersampled geographic areas. The presence of endochondral bone renews the hypothesis that this tissue is evolutionarily ancient and was lost secondarily in chondrichthyans ${ }^{7,8}$. This view is overall consistent with evidence of generalised bone loss in chondrichthyans, potentially as a result of the suppression of bone-generating molecular genetic pathways ${ }^{6,38}$. Continued work in Mongolia and re-evaluation of phylogenetic datasets will be necessary to address this, with the results likely to lead to substantial re-evaluation of gnathostome phylogeny.

Acknowledgements. M. Bolortsetseg generously assisted MDB with contacts and field experience in Mongolia. Fieldwork was supported by National Geographic Society grants CRE 8769-10 and GEFNE35-12 to MDB. ALJ's field contributions were supported by funds from the Anna Maria Lundin's stipend from Smålands Nation, Uppsala University. RS's field contributions were supported by a Royal Society Research Grant and the University of Manchester. The majority of this work was supported by the European Research Council (ERC) under the European Union's Seventh Framework Programme (FP/2007-2013)/ERC Grant Agreement number 311092 to MDB. RPD was also supported by the Île-de-France DIM (domaine d'intérêt majeur) matériaux anciens et patrimoniaux grant PHARE. Stig Walsh is thanked for access and loan of specimen at the National Museums of Scotland. 
262 Synchrotron tomography was performed at the ESRF (application LS 2451) with the assistance of Paul Tafforeau. SG was supported by a Royal Society Dorothy Hodgkin

Research Fellowship. Matt Friedman is thanked for undertaking the X-ray computed microtomography analysis. TNT was made available with the support of the Willi Hennig

266 Society.

Author Contributions: MDB conceived and designed the study. MDB, AJ, YAA, and EZ participated in all field seasons. RPD and AJ undertook preliminary CT scanning and segmentation that revealed the fossil was a 'placoderm' and had endochondral bone. RS discovered the first vertebrate remains in the first field season at Yamaat Gol in 2010. SG did most of the segmentation of Minjinia with input from MDB. AJ performed segmentation of Diplacanthus tissue. MC provided input on occipital comparative morphology of 'placoderms'. RPD provided data and comparative analyses and data for endoskeletal tissue. YAA provided background on the geology, palaeontology, and stratigraphy of the type location; EZ and YAA organized field logistics and permitting. MDB, SG, MC, RPD, and AJ undertook the anatomical interpretation and prepared the figures. MDB and SG conducted the phylogenetic analyses. RS conducted the parsimony branch support analyses. TG wrote the script for generating MrBayes partitions from TNT's character fits table and conducted the likelihood and model-fitting analyses. The manuscript was written by MDB, RPD, and SG.

Author Information:

284 Correspondence and requests for materials should be addressed to

285 m.brazeau@imperial.ac.uk.

\section{Methods} segmentation using Mimics 19.0 (http://biomedical.materialise.com/mimics; Materialise, 
296 Synchrotron light propagation phase contrast tomography. We imaged Diplacanthus crassismus specimen NMS 1891.92.334 on Beamline 19 of the European Synchrotron

Radiation Facility, using propagation phase-contrast synchrotron microtomography. We performed a spot scan with an energy of $116 \mathrm{keV}$, achieving a voxel size of $0.55 \mu \mathrm{m}$. We processed the resulting tomograms using VG StudioMax 2.2 (Volume Graphics, Germany), and prepared images in Blender.

302 Phylogenetic analysis. We conducted a parsimony analysis using TNT $1.5^{39}$ and Bayesian

303 analysis using MrBayes v 3.2.7 $7^{40}$. The dataset consisted of 95 taxa and 284 discrete

304 characters based on a pre-existing dataset ${ }^{41}$. We employed Osteostraci and Galeaspida as

305 composite outgroups. We conducted parsimony analysis using both equal weights and

306 implied weights methods. Global settings were 1000 search replicates and a hold of up to 1

307 million trees. Equal weights parsimony analyses were conducted using the ratchet with

308 default settings. Implied weights parsimony used a concavity parameter of 3 and the search

309 was without the ratchet. Command lists are included in Supplementary Information. We

310 conducted Bayesian analysis using both a partitioned and unpartitioned dataset. We used the

$311 \mathrm{Mkv}$ model $^{42}$ and gamma rate distribution. We ran the analyses for 5 million generations

312 with a relative burn-in fraction of 0.25 . Runs were checked for convergence using Tracer ${ }^{43}$.

313 We partitioned the dataset using a newly proposed method ${ }^{24}$ that partitions the data according

314 to homoplasy levels. Using the results of implied weights parsimony conducted in TNT, we

315 created a text table of character fit values. We wrote an $\mathrm{R}^{44}$ script to generate a list of

316 partition commands for MrBayes. To reduce the number of partitions with small numbers of

317 characters, we concatenated the partitions by rounding the fitness scores to 2 significant

318 figures, yielding 10 individual partitions.

319 We assessed parsimony ancestral states visually using Mesquite ${ }^{45}$. Likelihood and

320 Bayesian ancestral states were estimated in $\mathrm{R}$ using the castor package ${ }^{46}$. Prior to calculating

321 likelihood ancestral states on parsimony trees, we scaled branch lengths using PAUP*47 and

322 calculated the likelihood scores for all of the trees under the Mkv model. The trees were then

323 exported with branch lengths. To account for overall uncertainty in tree estimates, we

324 estimated ancestral states on 100 trees randomly selected from the fundamental set of most

325 parsimonious trees and two times 50 trees selected from the $75 \%$ last trees of each posterior

326 tree distribution from the Bayesian analysis. We then run an ancestral states estimation Mk

327 model (using the castor R package) using both the Equal Rates (ER) and All Rates Different

328 (ARD) models. This resulted in 400 ancestral states estimations. For each estimation we

329 extracted the overlap log likelihood, the AIC (counting one parameter for the ER model and 
330 two for the ARD model) and the scaled log likelihood (probability) for the presence and

331 absence of the endochondral bone character (character 4) for the last common node of

332 Minjinia and crown-group gnathostomes. We present the median value of these distributions

333 of the estimations overall log likelihoods, AICs and presence or absence of endochondral

334 bone in Extended Data Table 1.

\section{Data availability}

337 The holotype specimen of Minjinia turgenensis will be permanently deposited in the

338 collections of the Institute of Paleontology, Mongolian Academy of Sciences. Original

339 tomograms are available at (doi:10.6084/m9.figshare.12301229) and rendered models are

340 available at (doi:10.6084/m9.figshare.12301223). The phylogenetic character list and dataset

341 are available as Supplementary Information S1 and S2. The LifeScience Identifier for

342 Minjinia turgenensis is urn:lsid:zoobank.org:act:82A1CEEC-B990-47FF-927A-

343 D2F0B59AEA87

\section{Code availability}

346 R code for generating partitions based on character fits and code for likelihood ancestral

347 states reconstructions and plots are available in the Supplementary Information. 


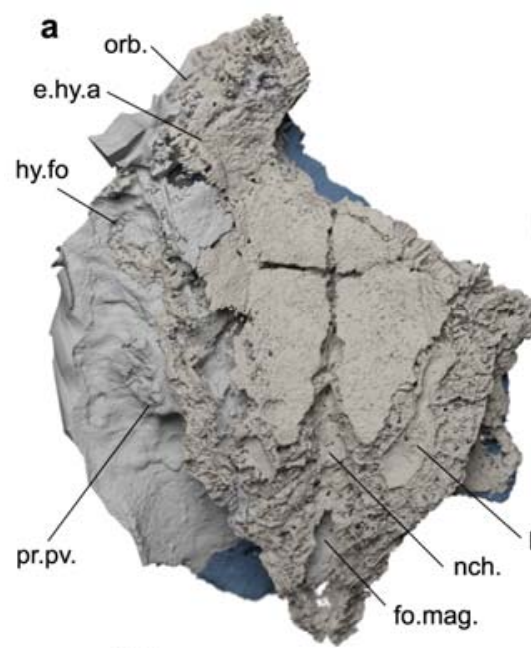

C

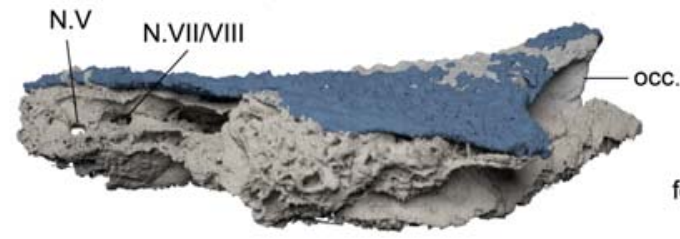

Fig. 1 | MPC-FH100/9.1 a 'placoderm' skull roof and braincase from the Early

351 Devonian of Mongolia. a, Ventral view. b, Dorsal view. c, Left lateral view. d, Posterior view. e, Braincase endocavity in dorsal view. Taupe: endoskeleton; grey: mould; pink: endocavity; blue: exoskeleton. a.scc., anterior semicircular canal; cav.end., endolymphatic cavity; crsp.ri, craniospinal ridge; d.end., endolymphatic duct; e.hy.a., sulcus for the efferent hyoid artery; f.m.ep., epaxial muscle fossa; fo.mag., foramen magnum; h.scc., horizontal semicicular canal; 1.d.ao, sulcus for the lateral dorsal aorta; N.V, trigeminal nerve canal; N.VII, facial nerve canal; N.VIII, acoustic nerve canal; N.X, vagus nerve canal; nch., notochordal canal; occ.ri, occipital ridge; orb., orbit; p.scc, posterior semicircular canal; pr.pv., paravagal process; sac., sacculus; soc., spino-occipital nerve canals. Scale bar, $20 \mathrm{~mm}$. 


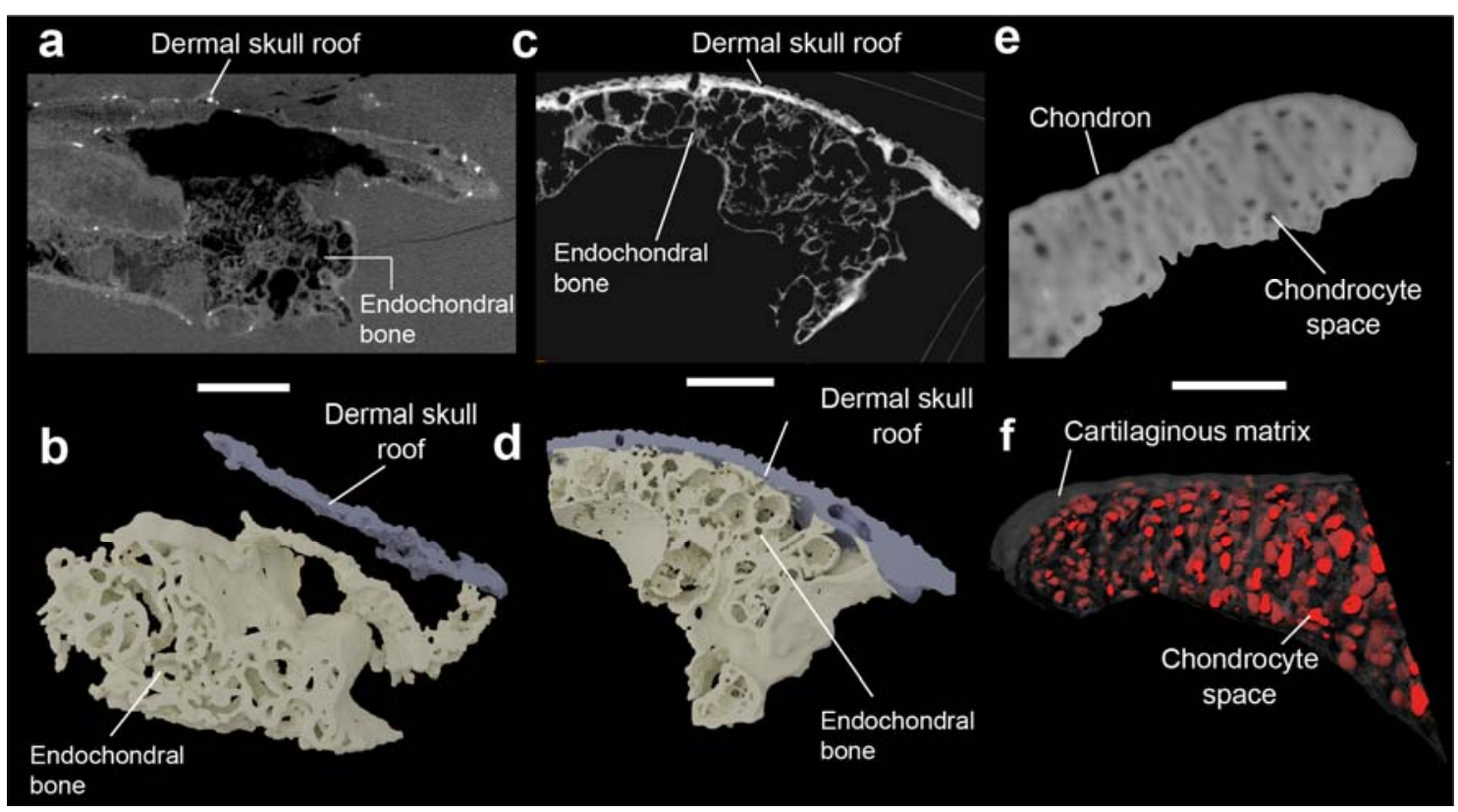

361 Fig. 2 | Endoskeletal mineralisation in fossil gnathostomes. a, Transverse tomographic

362 slice through MPC-FH100/9.1. b, Three-dimensional rendering of trabecular bone structure.

363 c, Transverse tomographic section through the braincase of the osteichthyan Ligulalepis. d,

364 Three-dimensional rendering of the trabecular bone in Ligulalepis (c and $\mathbf{d}$ use data from ${ }^{41}$ ).

365 e, Synchrotron tomography image of the calcified cartilage of the stem-group chondrichthyan

366 Diplacanthus crassisimus specimen NMS 1891.92.334. f, Semi-transparent three-

367 dimensional structure of calcified cartilage of NMS 1891.92.334. Scale bars, a and b, $10 \mathrm{~mm}$;

$368 \mathrm{c}$ and $\mathrm{d}, 1 \mathrm{~mm} ; \mathbf{c}$ and $\mathbf{h}, 150 \mu \mathrm{m}$. 


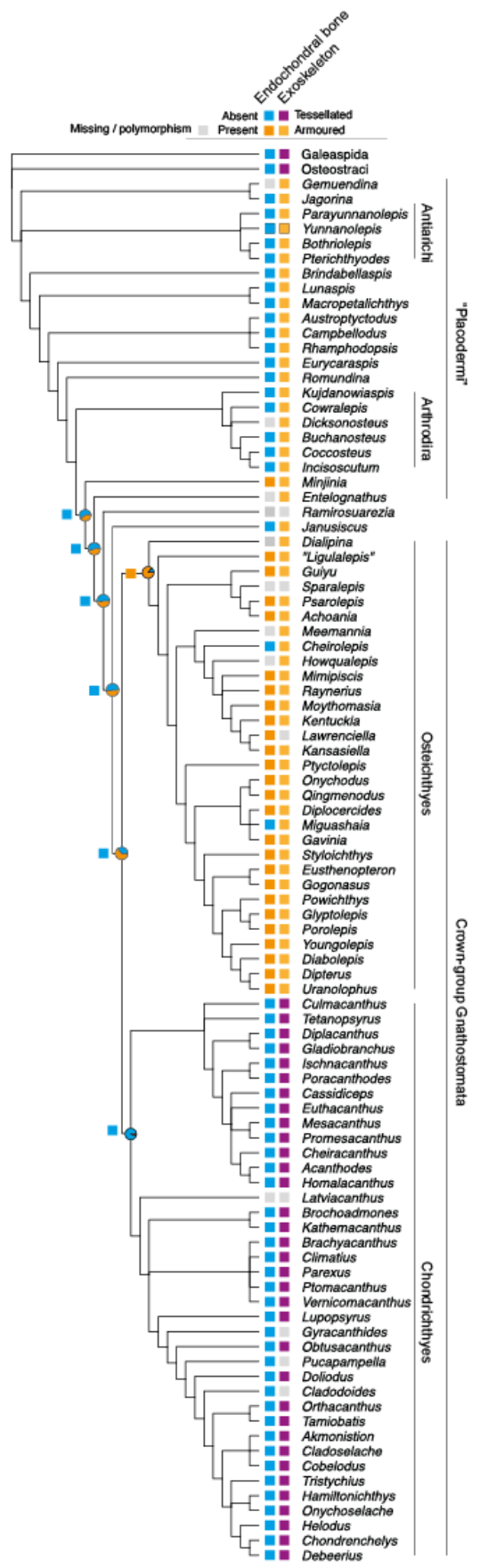

370 Fig. 3 | Summary phylogenetic relations of early gnathostomes showing distribution of

371 endochondral bone and exoskeletal armour. Squares at nodes indicate parsimony

372 reconstruction for endochondral bone. Pie charts at nodes show likelihood reconstructions for

373 the same character under the all-rates-different model (see Extended Data Figs $6 \& 7$ for

374 competing reconstructions). Grey box indicates uncertainty. Loss of endochondral bone maps

375 closely with generalised loss of bone in chondrichthyans where exoskeletal armour and

376 perichondral bone are also absent. 

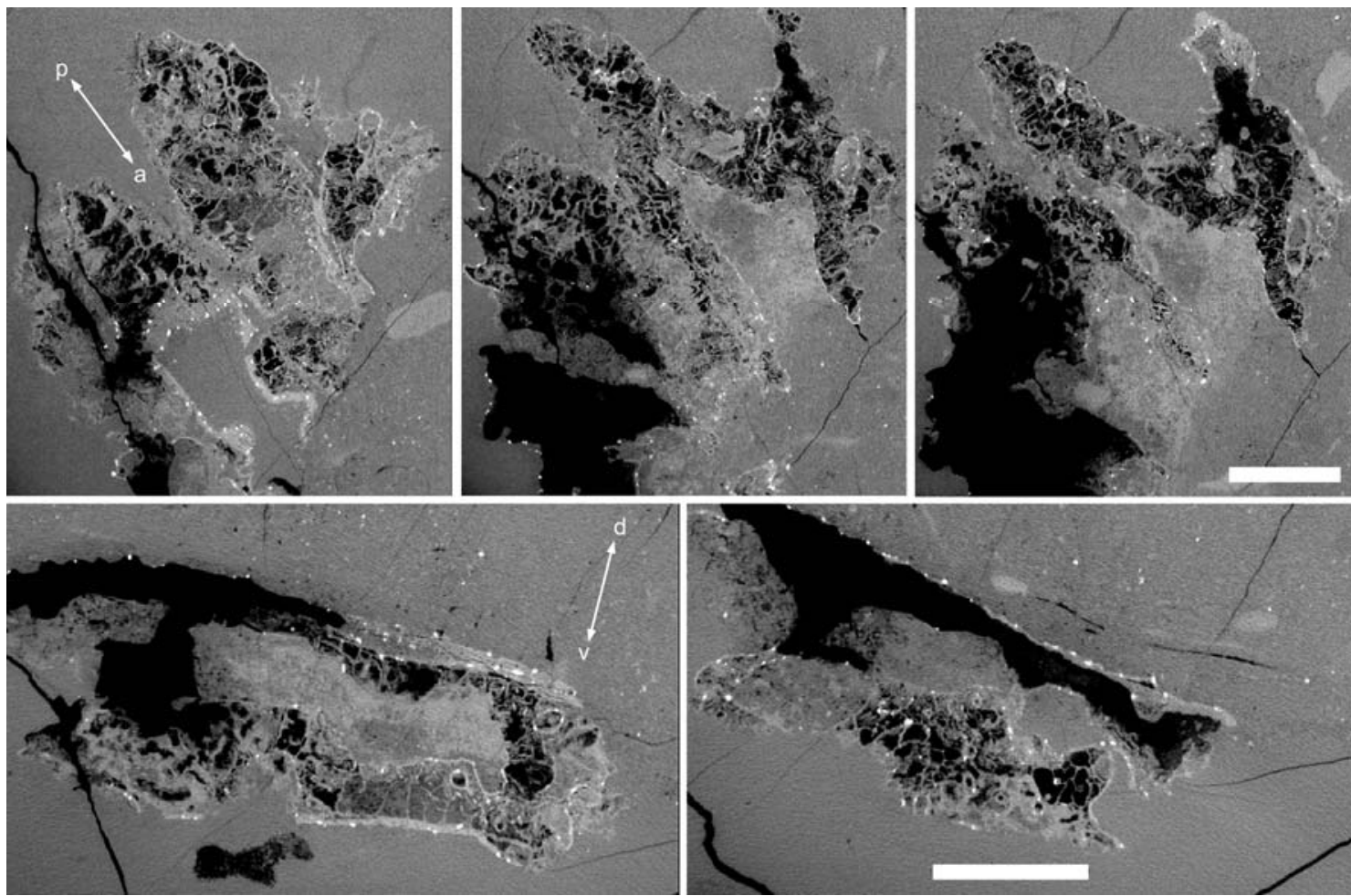

378 Extended Data Fig. 1 | Tomograms of endoskeletal ossification in Minjinia. Top row:

379 semi-coronal sections through braincase. Double-headed arrows indicate anterior-posterior

380 (a-p) dorsal-ventral (d-v) axes. Bottom row: semi-transverse sections through posterior part

381 of endocranium. Voids of black space represent mouldic preservation. Scale bars, $10 \mathrm{~mm}$ and

382 apply across each row of panels. 


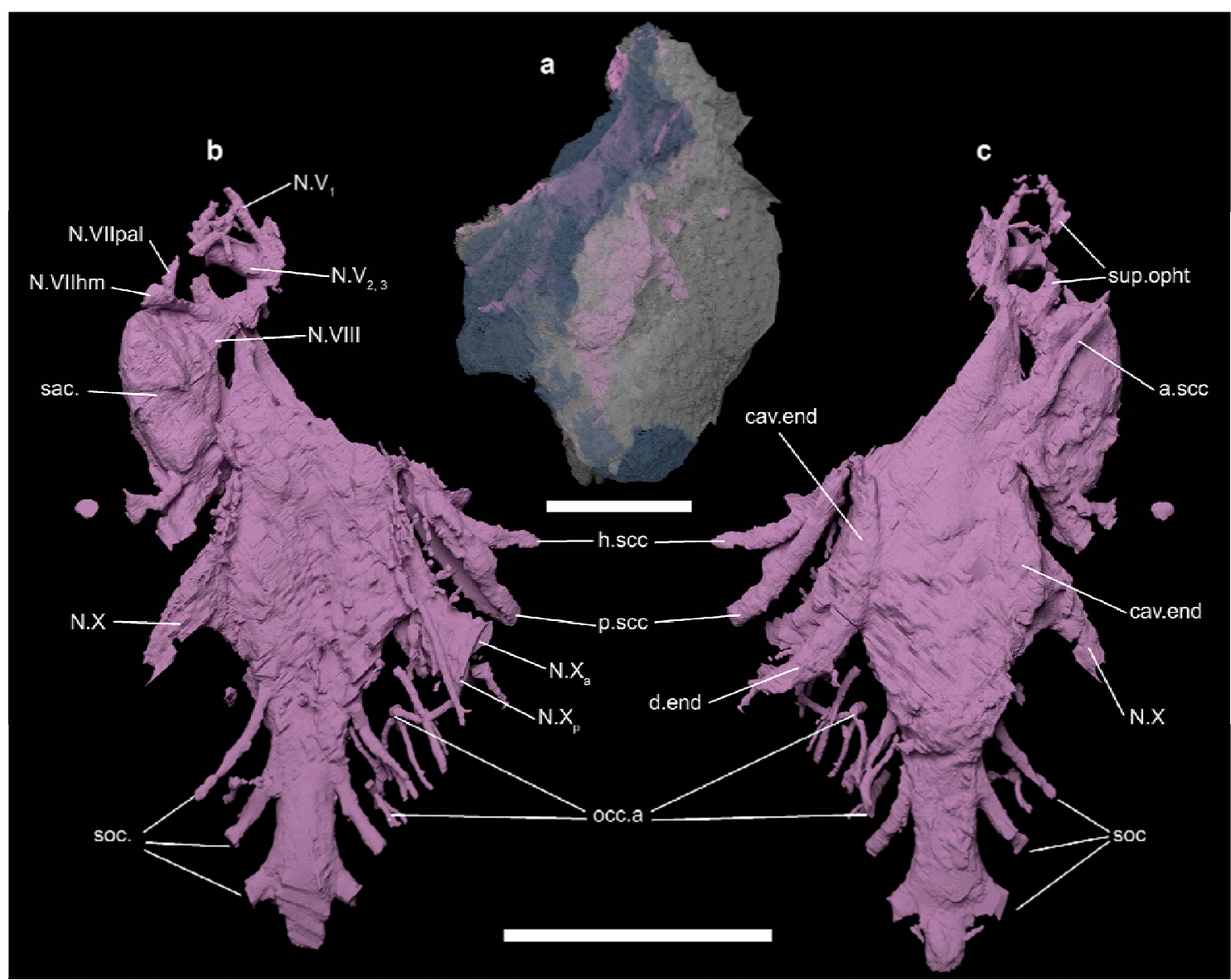

385 Extended Data Fig. 2 | Braincase endocavity of Minjinia. a, Semi-transparent rendering of

386 skull roof and braincase (grey and blue) showing extent of endocavity (pink). b, Ventral

387 view. c, Dorsal view. a.scc., anterior semicircular canal; cav.end., endolymphatic cavity;

388 d.end., endolymphatic duct; h.scc., horizontal semicicular canal; 1.d.ao., sulcus for the lateral

389 dorsal aorta; N.V, trigeminal nerve canal; N.VIIhm, hyomandibular branch of facial nerve

390 canal; N.VIIpal, palatine branch of facial nerve canal; N.VIII, acoustic nerve canal; N.X,

391 vagus nerve canal, N.X $\mathrm{X}_{\mathrm{a}}$, anterior branch of vagus nerve canal; N.Xp, posterior branch of

392 vagus nerve canal; occ.a, occipital artery canals; p.scc, posterior semicircular canal; sac.,

393 sacculus; soc., spino-occipital nerve canals; sup.opth, canal for supra-ophtalmic nerve. Scale

394 bars, $20 \mathrm{~mm}$ (upper scale bar associates with a, lower scale bar associates with $\mathbf{b}$ and $\mathbf{c}$ ). 


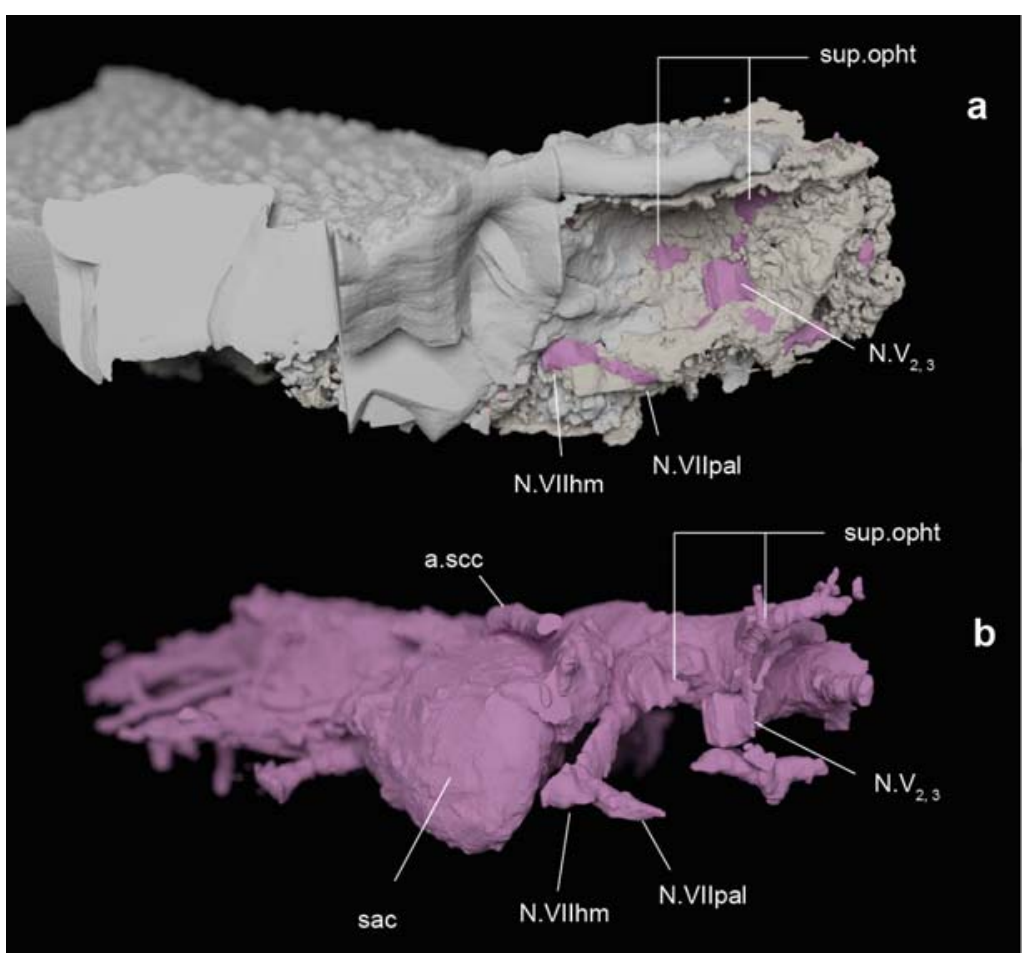

398 Extended Data Fig. 3 | Right orbital wall and innervation pattern of Minjinia. a, orbit in

399 anterolateral view showing disposition of nerve openings (pink infill). b, endocast in the

400 same perspective showing the relationship between never canals and endocast. 
Parsimony: Equal weights

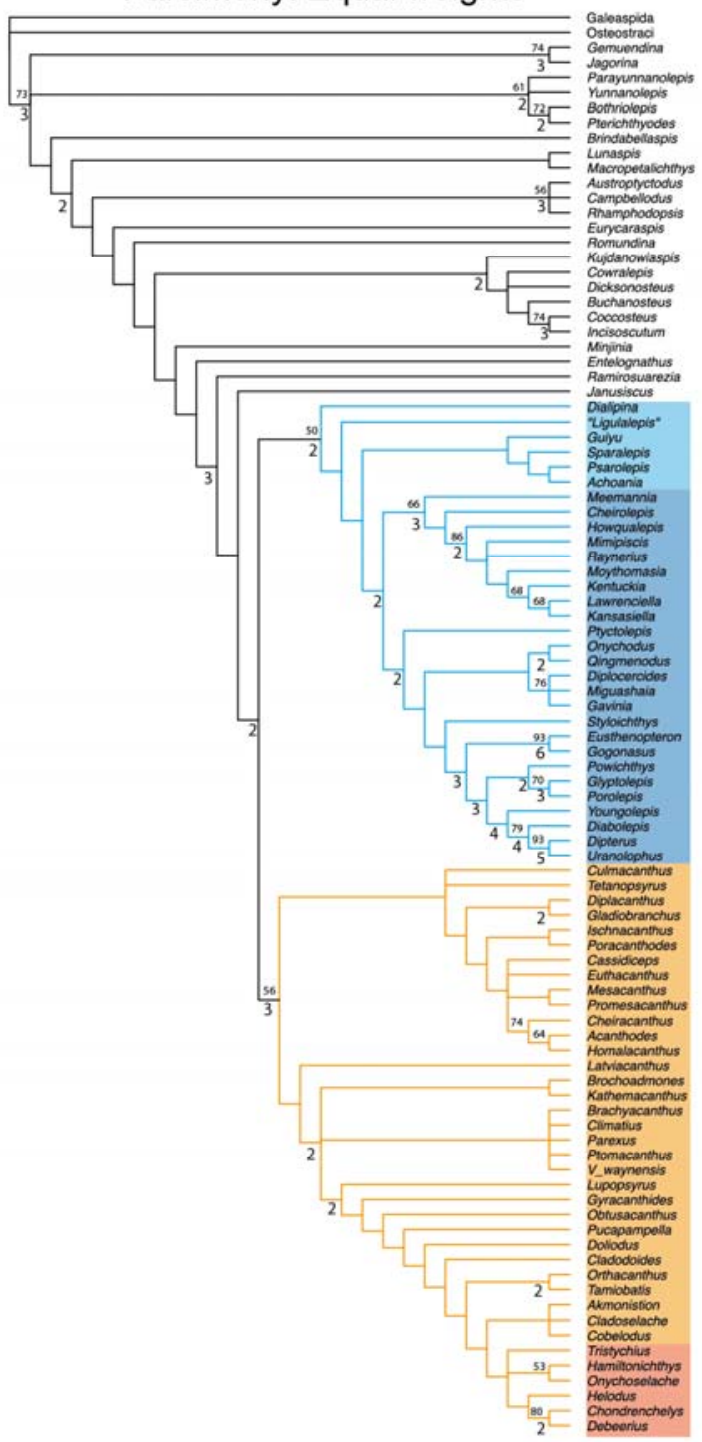

Parsimony: Implied weights

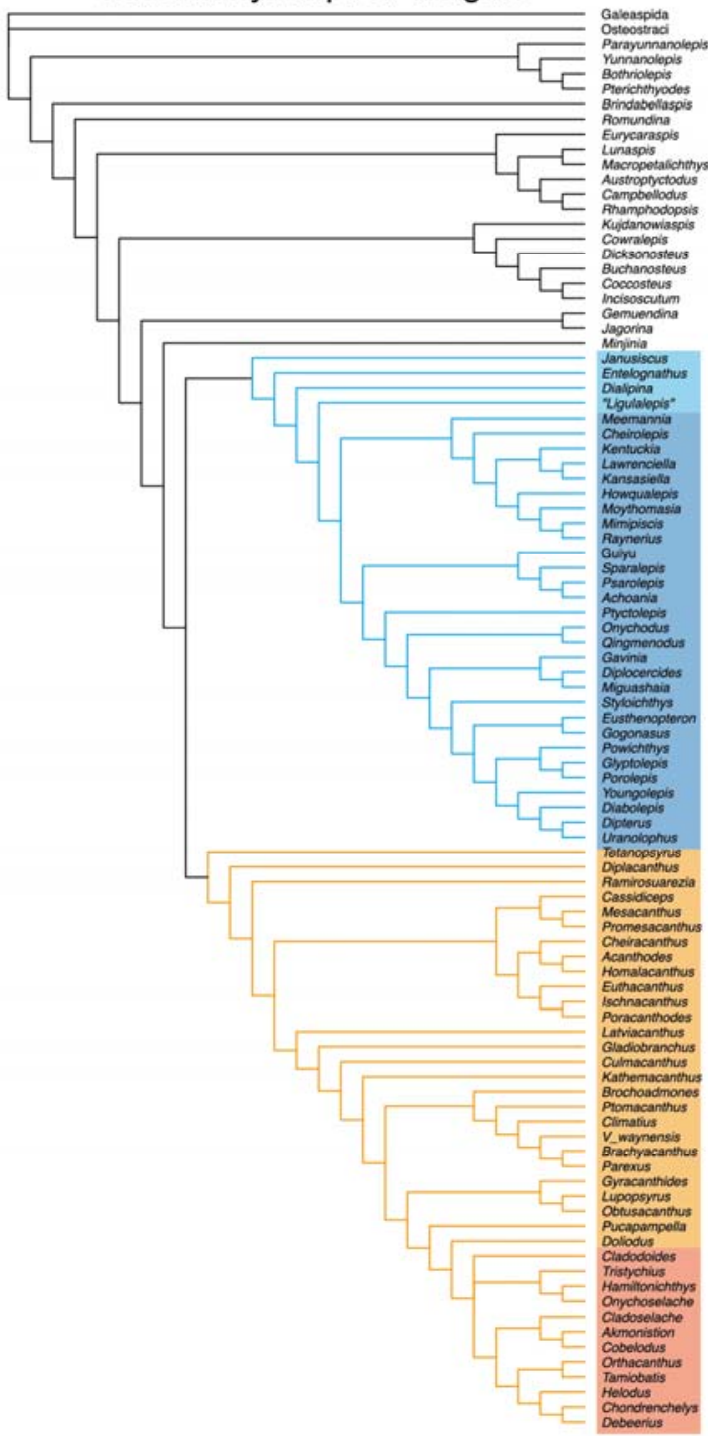

403 Extended Data Fig. 4 | Results of phylogenetic parsimony analysis. Dataset consists of 95

404 taxa and 284 characters. Both trees are strict consensus topologies. Equal weights parsimony

405 analysis using the ratchet resulted in 240 trees with a length of 832 steps. Implied weights

406 parsimony analysis using random addition sequence + branch-swapping resulted in two

407 optimal trees with score 85.23240. Double-digit figures above internal branches are bootstrap

408 values of 50\% and over; single-digit figures below branches are Bremer decay index values.

409 Blue shading: osteichthyan total group (dark blue: crown group); orange shading:

410 chondrichthyan total group (dark orange: crown group). 
bioRxiv preprint doi: https://doi.org/10.1101/2020.06.09.132027; this version posted June 10,2020. The copyright holder for this preprint (which was not certified by peer review) is the author/funder, who has granted bioRxiv a license to display the preprint in perpetuity. It is made available under aCC-BY-NC-ND 4.0 International license.

Bayesian: unpartitioned

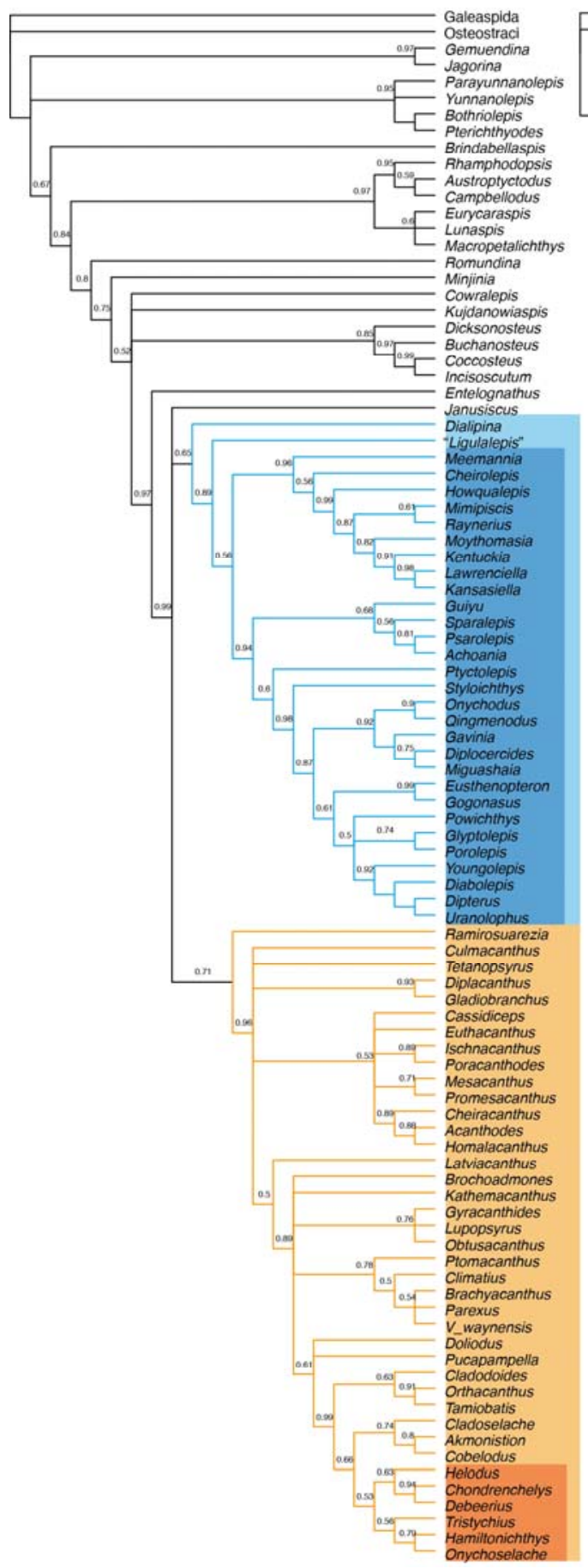

Bayesian: homoplasy partitioned

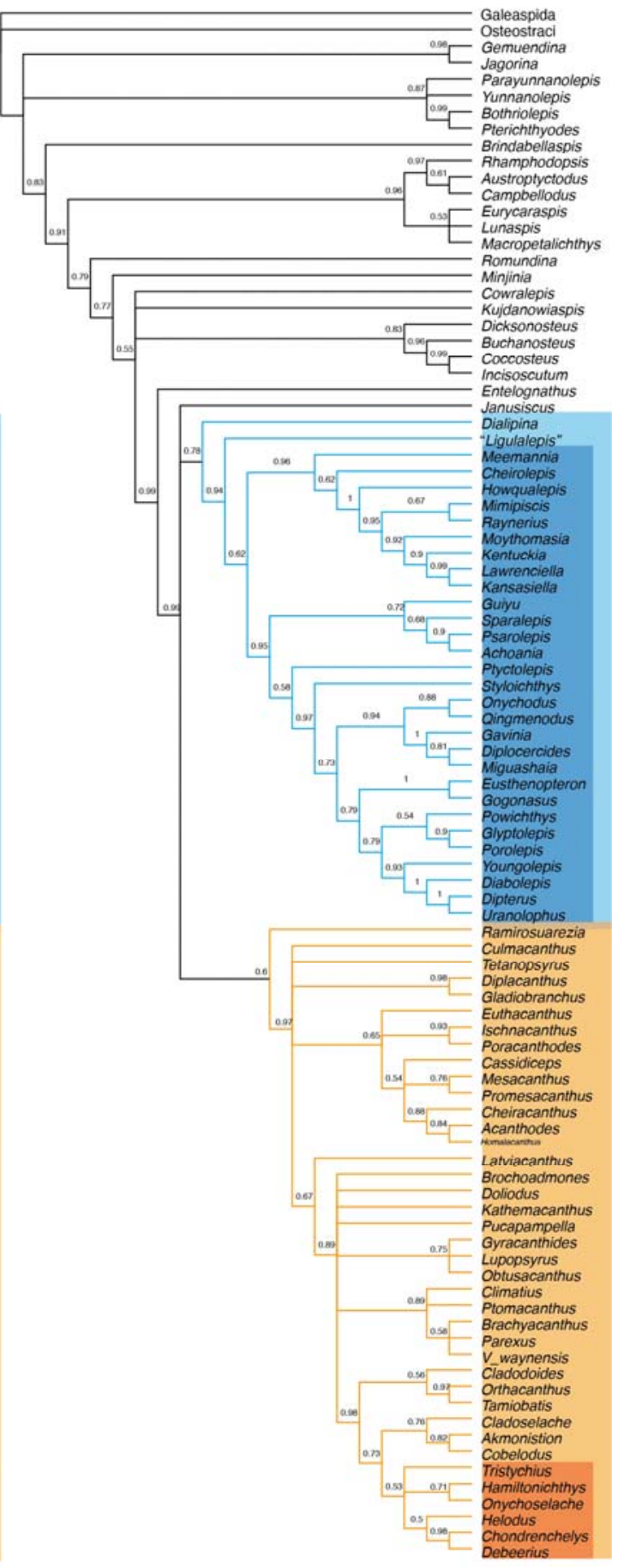

Extended Data Fig. 5 | Results of Bayesian phylogenetic analysis using both partitioned

414 and unpartitioned data. Majority-rules consensus trees with posterior probabilities shown

415 along branches. Blue shading: osteichthyan total group (dark blue: crown group); orange

416 shading: chondrichthyan total group (dark orange: crown group). 
bioRxiv preprint doi: https://doi.org/10.1101/2020 06.09.132027: this version posted June 10, 2020. The copyright holder for this preprint (which was not certified by peer review) is the author/funder, who has granted bioRxiv a license to display the preprint in perpetuity. It is made available under aCC-BY-NC-ND 4.0 International license.

\section{Endochondral bone estimation (parsimony - ARD)}

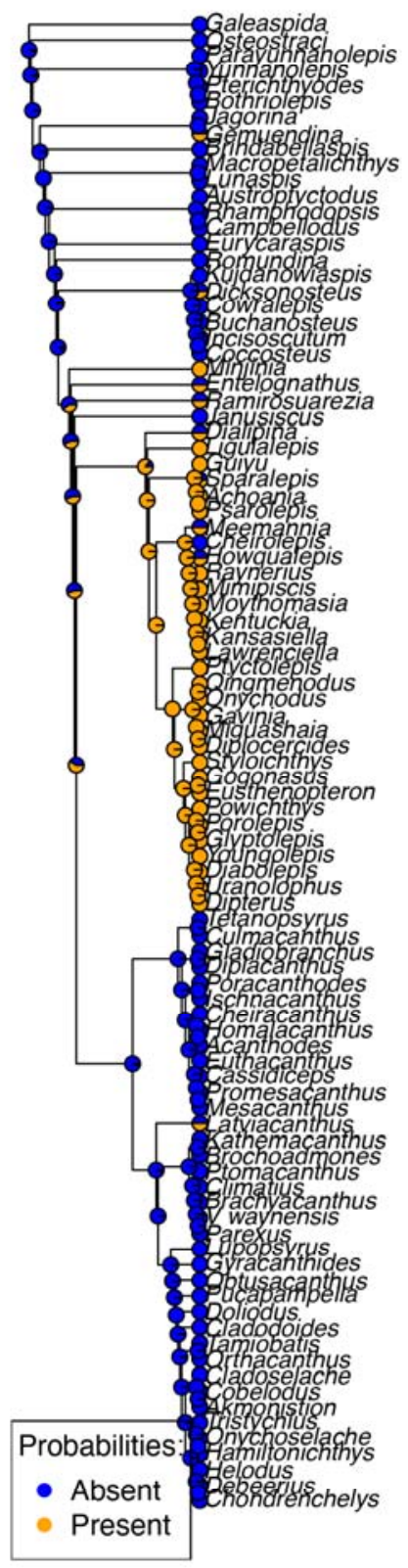

\section{Endochondral bone estimation (parsimony - ER)}

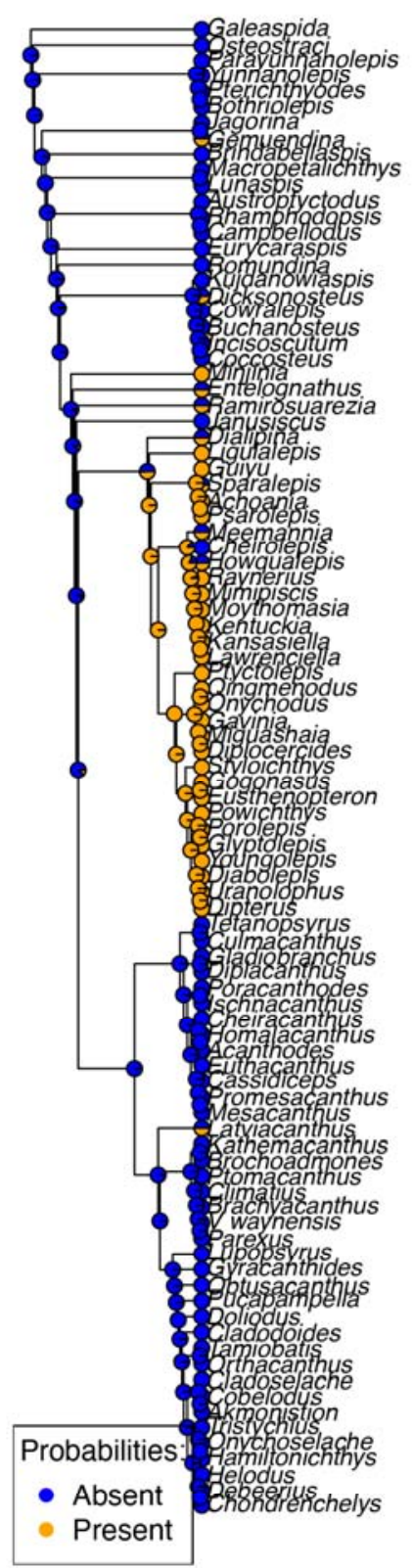


bioRxiv preprint doi: https://doi.org/10.1101/2020.06.09.132027: this version posted June 10,2020. The copyright holder for this preprint (which was not certified by peer review) is the author/funder, who has granted bioRxiv a license to display the preprint in perpetuity. It is made available under aCC-BY-NC-ND 4.0 International license.

\section{Endochondral bone estimation (bayesian - ARD)}

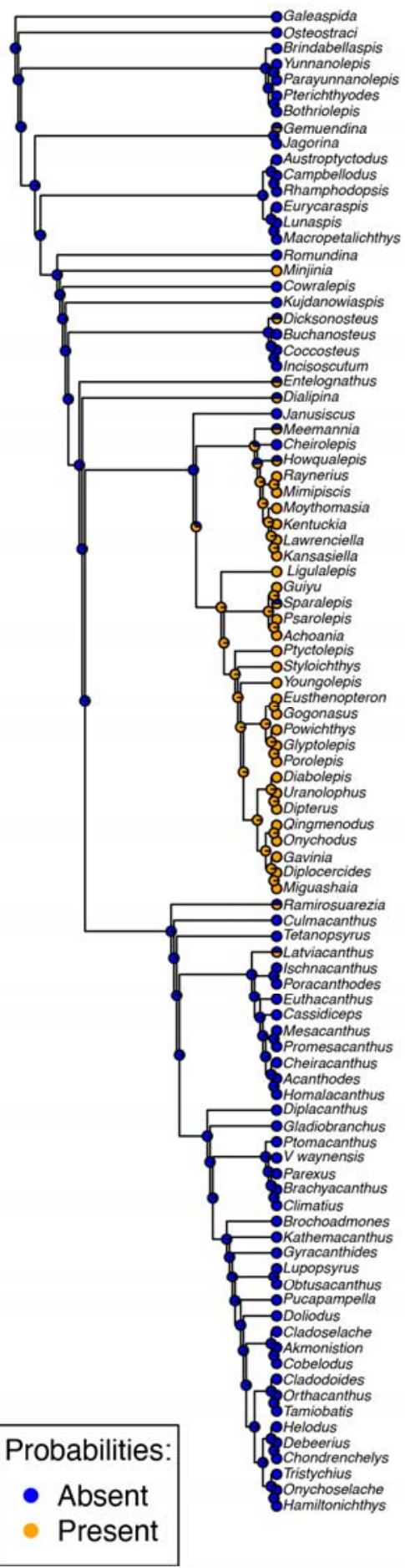

\section{Endochondral bone estimation (bayesian - ER)}

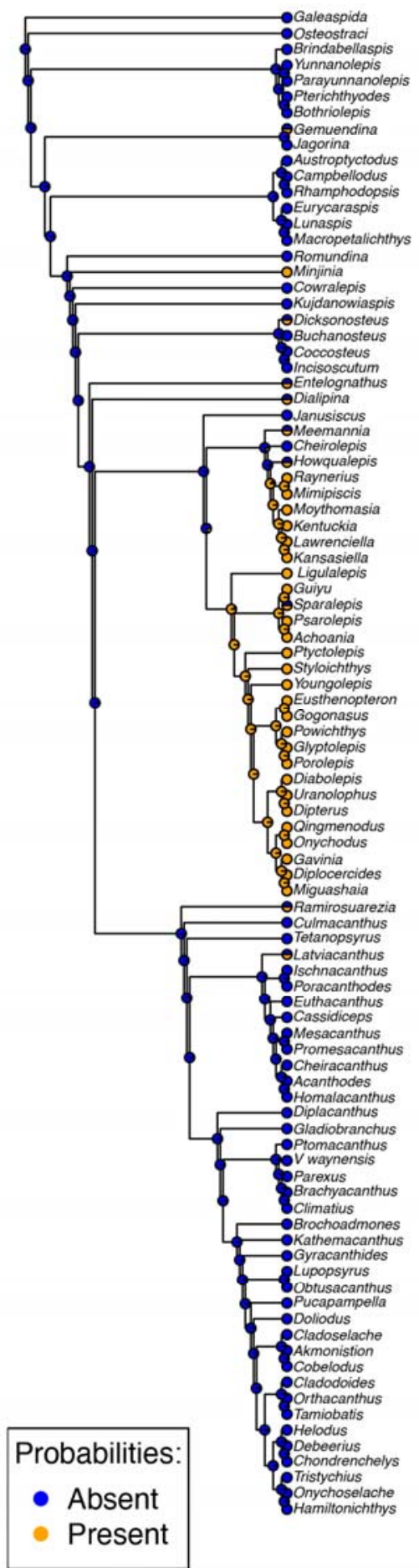

423 unpartitioned Bayesian analysis results. ARD, all rates different model; ER, equal rates 424 model. 
425 Extended Data Table 1 | Tree distribution (100) ancestral states estimation results. ER =

426 Equal rates model; ARD = All Rates Different model. The columns AIC and log.lik represent

427 the median AIC and log.lik across the 100 parsimony and bayesian trees (for both models).

428 The columns Absent and Present represent the median scaled likelihood for the endochondral

429 bone state.

Node Tree Model log.lik AIC Absent Present

$\begin{array}{lllllll}\text { Minjinia:crown gnathostomes } & \text { Parsimony } & \text { ER } & -27.60 & 57.20 & 0.94 & 0.06\end{array}$

$\begin{array}{llllll} & \text { ARD } & -25.47 & 54.93 & 0.61 & 0.39 \\ \text { Bayesian } & \text { ER } & -29.94 & 61.89 & 0.98 & 0.02 \\ & \text { ARD } & -27.69 & 59.38 & 0.82 & 0.18\end{array}$

430

431

432

433

434

435

436

437

438

439

440

441

442

443

444

445

446

447

448

449

450

451

452

453

454

455

456

457

458

459

460

461

\section{References}

1. Hall, B. K. Bones and Cartilage. (Academic Press, 2005).

2. Janvier, P. Early Vertebrates. (Oxford University Press, 1996).

3. Friedman, M. \& Brazeau, M. A Reappraisal of the Origin and Basal Radiation of the Osteichthyes. J Vertebr Paleontol 30, 36-56 (2010).

4. Brazeau, M. D. \& Friedman, M. The characters of Palaeozoic jawed vertebrates. Zool J Linn Soc 170, 779-821 (2014).

5. Eames, B. F. et al. Skeletogenesis in the swell shark Cephaloscyllium ventriosum. Journal of Anatomy 210, 542-554 (2007).

6. Marconi, A., Hancock-Ronemus, A. \& Gillis, J. A. Adult chondrogenesis and spontaneous cartilage repair in the skate, Leucoraja erinacea. eLife Sciences 9, 2813 (2020).

7. Maisey, J. G. Heads and tails: a chordate phylogeny. Cladistics 2, 201-256 (1986).

8. Zhu, M. Bone gain and loss: insights from genomes and fossils. Natl Sci Rev 1, 490492 (2014).

9. Alekseeva, R. E., Mendbayar, B. \& Erlanger, O. A. Brachiopods and Biostratigraphy of the Lower Devonian of Mongolia. 16, (Nauka, 1981).

10. Alekseeva, R. E. Devonian Biostratigraphy of Mongolia. (Nauka, 1993).

11. Mark-Kurik, E. in Morphology, Phylogeny and Paleobiogeography of Fossil Fishes (eds. Elliott, D. K., Maisey, J., Yu, X. \& Miao, D.) 101-106 (2010).

12. Stensiö, E. A. Contributions to the knowledge of the vertebrate fauna of the Silurian and Devonian of western Podolia. II. Notes on two arthrodires from the Downtonian of Podolia. 35A, 1-83 (1944).

13. Ørvig, T. Description, with special reference to the dermal skeleton, of a new radotinid arthrodire from the Gedinnian of Arctic Canada. Colloque international C.N.R.S. no. 218 43-71 (1975).

14. Vaškaninová, V. \& Ahlberg, P. E. Unique diversity of acanthothoracid placoderms (basal jawed vertebrates) in the Early Devonian of the Prague Basin, Czech Republic: A new look at Radotina and Holopetalichthys. PLoS ONE 12, e0174794 (2017). 
462

463

464

465

466

467

468

469

470

471

472

473

474

475

476

477

478

479

480

481

482

483

484

485

486

487

488

489

490

491

492

493

494

495

496

497

498

499

500

501

502

503

504

505

506

507

508

509

510

511

15. Wängsjö, G. The Downtonian and Devonian vertebrates of Spitsbergen. IX. Norsk Polarinstitutt Skrifter 97, 1-611 (1952).

16. Charest, F., Johanson, Z. \& Cloutier, R. Loss in the making: absence of pelvic fins and presence of paedomorphic pelvic girdles in a Late Devonian antiarch placoderm (jawed stem-gnathostome). Biology Letters 14, 20180199 (2018).

17. Dupret, V., Sanchez, S., Goujet, D. \& Ahlberg, P. E. The internal cranial anatomy of Romundina stellina Ørvig, 1975 (Vertebrata, Placodermi, Acanthothoraci) and the origin of jawed vertebrates-Anatomical atlas of a primitive gnathostome. PLOS ONE 12, e0171241 (2017).

18. Olive, S., Goujet, D., Lelièvre, H. \& Janjou, D. A new Placoderm fish (Acanthothoraci) from the Early Devonian Jauf Formation (Saudi Arabia). Geodiversitas 33, 393-409 (2011).

19. Stensiö, E. A. La cavité labyrinthique, l'ossification sclérotique et l'orbite de Jagorina. Colloques internationaux du Centre national de la Recherche scientifique 21, 9-43 (1950).

20. Stensiö, E. A. Anatomical studies on the arthrodiran head. K Sven Vetenskapsakad Handl 9, 1-419 (1963).

21. Goujet, D. Les poissons placodermes du Spitsberg. (Cahiers de Paléontologie, Editions du CNRS, 1984).

22. Davis, S. P., Finarelli, J. A. \& Coates, M. I. Acanthodes and shark-like conditions in the last common ancestor of modern gnathostomes. Nature 486, 247-250 (2012).

23. Castiello, M. \& Brazeau, M. D. Neurocranial anatomy of the petalichthyid placoderm Shearsbyaspis oepiki Young revealed by $\mathrm{X} \square$ ray computed microtomography.

Palaeontology 21, 754 (2018).

24. Rosa, B. B., Melo, G. A. R. \& Barbeitos, M. S. Homoplasy-Based Partitioning Outperforms Alternatives in Bayesian Analysis of Discrete Morphological Data. Systematic Biology 54, 373 (2019).

25. Rosen, D. E., Forey, P. L., Gardiner, B. G. \& Patterson, C. Lungfishes, tetrapods, paleontology, and plesiomorphy. Bull Am Mus Nat Hist 167, 159-276 (1981).

26. Gardiner, B. G. The relationships of the palaeoniscid fishes, a review based on new specimens of Mimia and Moythomasia from Upper Devonian of Western Australia. Bull Br Mus nat Hist (Geol) 37, 173-428 (1984).

27. Zhu, M. et al. A Silurian placoderm with osteichthyan-like marginal jaw bones. Nature 502, 188-193 (2013).

28. Giles, S., Friedman, M. \& Brazeau, M. D. Osteichthyan-like cranial conditions in an Early Devonian stem gnathostome. Nature 520, 82-85 (2015).

29. Miles, R. S. in Interrelationships of Fishes (eds. Greenwood, P. H., Miles, R. S. \& Patterson, C.) 63-103 (Academic Press London, 1973).

30. Janvier, P. Les céphalaspides du Spitsberg. (Éditions du Centre National de la Recherche Scientifique, 1985).

31. Young, G. C. New information on the structure and relationships of Buchanosteus (Placodermi: Euarthrodira) from the Early Devonian of New South Wales. Zool J Linn Soc 66, 309-352 (1979).

32. Stensiö, E. A. On the head of the macropetalichthyids. Field Museum of Natural History Publication Geological Series 4, 87-197 (1925).

33. Ørvig, T. Notes on some Paleozoic lower vertebrates from Spitsbergen and North America. Norsk Geologisk Tidsskrift 37, 285-353 (1957).

34. Schaeffer, B. The braincase of the holostean fish Macrepistius, with comments on neurocranial ossification in the Actinopterygii. American Museum Novitates 2459, 134 (1971). 
512

513

514

515

516

517

518

519

520

521

522

523

524

525

526

527

528

529

530

531

532

533

534

535

536

537

538

539

540

541

35. Cloutier, R. in Devonian Fishes and Plants (eds. Schultze, H.-P. \& Cloutier, R.) 227247 (Verlag Dr. Friedrich Pfeil, 1996).

36. Grande, L. \& Bemis, W. E. Osteology and Phylogenetic Relationships of Fossil and Recent Paddlefishes (Polyodontidae) with Comments on the Interrelationships of Acipenseriformes. Memoir (Society of Vertebrate Paleontology) 11 (Supplement to Number 1), 1-121 (1991).

37. Venkatesh, B. et al. Elephant shark genome provides unique insights into gnathostome evolution. Nature 505, 174-179 (2014).

38. Ryll, B., Sanchez, S., Haitina, T., Tafforeau, P. \& Ahlberg, P. E. The genome of Callorhinchus and the fossil record: a new perspective on SCPP gene evolution in gnathostomes. Evolution \& Development 16, 123-124 (2014).

39. Goloboff, P. A. \& Catalano, S. A. TNT version 1.5 , including a full implementation of phylogenetic morphometrics. Cladistics 32, 221-238 (2016).

40. Ronquist, F. \& Huelsenbeck, J. P. MrBayes 3: Bayesian phylogenetic inference under mixed models. Bioinformatics 19, 1572-1574 (2003).

41. Clement, A. M. et al. Neurocranial anatomy of an enigmatic Early Devonian fish sheds light on early osteichthyan evolution. eLife Sciences 7, e34349 (2018).

42. Lewis, P. O. A likelihood approach to estimating phylogeny from discrete morphological character data. Systematic Biology 50, 913 (2001).

43. Rambaut, A., Drummond, A. J., Xie, D., Baele, G. \& Suchard, M. A. Posterior Summarization in Bayesian Phylogenetics Using Tracer 1.7. Systematic Biology 67, 901-904 (2018).

44. $\quad \mathrm{R}$ Core Team. $R$ : A language and environment for statistical computing. ( $\mathrm{R}$ Foundation for Statistical Computing, 2019).

45. Maddison, D. R. \& Maddison, W. P. Mesquite. (2019).

46. Louca, S. \& Doebeli, M. Efficient comparative phylogenetics on large trees. Bioinformatics 34, 1053-1055 (2017).

47. Swofford, D. L. PAUP*. 4.0a166, (2019). 